\title{
Micropollutant removal by advanced oxidation of microfiltered secondary effluent for water reuse
}

\author{
Christopher P James $^{\mathrm{a}}$, Eve Germain ${ }^{\mathrm{a}}$ and Simon Judd ${ }^{\mathrm{b}} *$ \\ ${ }^{a}$ Thames Water R\&D, Innovation Centre, Island Road, Reading, Berks RG2 0RP, UK \\ ${ }^{\mathrm{b}}$ Cranfield Water Science Institute, Cranfield University, Cranfield, Beds MK43 0AL, UK \\ *corresponding author, s.j.judd@ cranfield.ac.uk. +44 1234758310
}

\section{Abstract}

The removal of micropollutants (MPs) from secondary municipal wastewater by an advanced oxidation process (AOP) based on UV irradiation combined with hydrogen peroxide $\left(\mathrm{UV} / \mathrm{H}_{2} \mathrm{O}_{2}\right)$ has been assessed through pilot-scale experiments incorporating microfiltration (MF) and reverse osmosis (RO). Initial tests employed low concentrations of a range of key emerging contaminants of concern, subsequently focusing on the highly recalcitrant compound metaldehyde (MA), and the water quality varied by blending MF and RO permeate.

Under optimum $\mathrm{H}_{2} \mathrm{O}_{2}$ and lamp power conditions, AOP achieved significant removal (>99\%) of N-nitrosodimethylamine (NDMA) and endocrine disrupting compounds (EDCs) for all waters. Pesticide removal, in particular metaldehyde, atrazine and 2, 4 5Trichlorophenoxyacetic acid, was dependent on water transmittance (UVT), and levels of TOC and other hydroxyl radical $(\mathrm{OH})$ scavengers. Further analysis of MA removal showed UVT, hydraulic retention time and $\mathrm{H}_{2} \mathrm{O}_{2}$ dose to be influential parameters in determining degradation as a function of UV dose.

A cost assessment revealed energy consumption to account for $65 \%$ of operating expenditure with lamp replacement contributing $25 \%$. A comparison of three unit process sequences, based on MF, RO, AOP and activated carbon (AC), revealed MF-RO-AOP to be the most cost effective provided management of the RO concentrate stream incurred no significant cost. Results demonstrated AOPs to satisfactorily reduce levels of the more challenging recalcitrant MPs to meet stringent water quality standards for wastewater reuse, but that practical limitations exist and the cost penalty significant.

Keywords: Advanced oxidation; Wastewater reuse; Micropollutants; Metaldehyde; Operating cost.

\section{Introduction}

Over the past 20 years, there has been increased awareness of the incidence of certain micropollutants (MPs) in the environment and a concomitant increase in the study of their fate and removal by water treatment technologies. This is particularly germane to recovered and reused wastewater, which demands implementation of advanced treatment technologies to attain water of a quality comparable to treated raw waters with respect to the MP levels.

MPs can cause potentially adverse health effects at concentrations in the milligram/ nanogram per litre range (Holm, 2011). They may originate from natural or anthropogenic sources, such as industry, agriculture and domestic households. Environmental quality 
standards for several organic MPs that may be released into surface waters have been promulgated via regulations such as the European Water Framework Directive (WFD) (EC, 2000). However, there are several other emerging chemicals of concern that are currently unregulated and not monitored, particularly in wastewater effluents. Specifically, the difficulty in effectively managing and reliably treating diffuse sources of pollution poses a significant challenge to wastewater reclamation, especially if intended for human consumption.

Research into removal or fate of MPs has mainly focused on organic compounds often classified as disinfection by-products (DBPs), pharmaceuticals, pesticides, and endocrine disrupting compounds (EDCs). EDCs are widespread in the environment and consist of natural oestrogens (estrone (E1) and 17 $\beta$-estradiol (E2)) along with synthetic xenoestrogens (17 $\alpha$-ethynylestradiol), phthalates and many more, known to affect/interfere with the action of hormones in the endocrine system (Hotchkiss et al., 2008). Sewage effluents have been identified as being a major source of natural estrogenic chemicals in the aquatic environment (Desbrow et al., 1996). Research conducted over the past 15-20 years has highlighted the limited removal capability of conventional wastewater treatment systems to levels that are deemed acceptable.

The use and type of pesticides for wide-ranging applications within the agricultural sector has developed significantly over the past 50 years, and these can readily contaminate raw drinking water sources through run-off. Regulatory limits for pesticide levels in EU drinking waters are $0.1 \mu \mathrm{g} \mathrm{L}^{-1}$ for an individual pesticide and $0.5 \mu \mathrm{g} \mathrm{L}^{-1}$ in total. Among those of concern in drinking waters are atrazine and, most recently, metaldehyde (MA). The latter has been shown to be widely detected in UK water sources (Water UK, 2009) and is not readily removed by conventional water treatment technologies (Autin et al., 2012).

Advanced oxidation processes (AOPs), characterised by the generation of highly reactive, non-selective hydroxyl radicals $(\mathrm{OH})$, offer a promising alternative to conventional treatment for removing organic constituents in contaminated waters. The $\mathrm{UV} / \mathrm{H}_{2} \mathrm{O}_{2}$ process is amongst the most studied AOP and reported to be effective at degrading recalcitrant MPs such as NDMA (Poussade et al., 2009) and various pharmaceuticals and EDCs (Benotti et al., 2009; Snyder et al., 2007) for indirect potable reuse (IPR) and, in the case of surface water treatment generally, metaldehyde (Autin et al., 2013). Such a process installed downstream of the membrane filtration step of an IPR scheme to remove traces of compounds permeating the RO membrane (Royce et al., 2010) can potentially achieve full mineralisation of MPs (Matilainen and Sillanpää, 2010), whereas reverse osmosis (RO) leaves MPs unchanged in the waste stream thus demanding further management. However, both RO and AOPs are energy and chemically intensive and thus incur a significant cost. Whilst previous studies of AOPs at bench scale have elucidated degradation mechanisms and $\mathrm{H}_{2} \mathrm{O}_{2}$ dosing requirements (or hydroxyl rate constants) for MP removal (Sanches et al., 2010; Rosario-Ortiz et al., 2010; Katsoyiannis et al., 2011; Baeza and Knappe, 2011), representative costs and performance from larger scale demonstration against real waters have not been quantified.

This study aims to determine both the effectiveness and cost of a $\mathrm{UV} / \mathrm{H}_{2} \mathrm{O}_{2}$ process for treating MPs of emerging concern, and the most highly recalcitrant of these in particular MA, which currently presents a significant challenge to the water industry. Impacts of key parameters, specifically feedwater transmittance, are assessed and process costs compared with those of other candidate processes recently demonstrated on the same large pilot scale. 


\section{Materials and methods}

\subsection{Pilot plant and chemical reagents}

The pilot plant (Fig. 1), details of which are provided elsewhere (Raffin et al, 2011), treated $600 \mathrm{~m}^{3} \mathrm{~d}^{-1}$ of final effluent from a conventional activated sludge (CAS)-based wastewater treatment works. The process consisted of a pre-filter, microfiltration (MF), reverse osmosis (RO) and an advanced oxidation process (AOP), based on a combination of UV irradiation and $\mathrm{H}_{2} \mathrm{O}_{2}$ dosing $\left(\mathrm{UV} / \mathrm{H}_{2} \mathrm{O}_{2}\right)$, downstream of the $\mathrm{MF}$ (AOP1) and the RO (AOP2).

Each AOP comprised a flow-through UV reactor (Trojan UVPhox ${ }^{\mathrm{TM}}$, Model 12AL30) equipped with 12 low-pressure/high-output (LP/HO) amalgam lamps with nominal output power from the lamps varies from 60 to $100 \%$. AOP1 reactor was fitted with an automatic sleeve wiping and clean-in-place (CIP) system, the latter using citric acid for iron fouling mitigation or scaling on the quartz sleeves (i.e. fouling).. $\mathrm{H}_{2} \mathrm{O}_{2}$ was dosed upstream of both UV reactors with static mixers in-line. UV transmittance (at $254 \mathrm{~nm}$ ), intensity and power were monitored online for each reactor, along with temperature, and independent flowmeters fitted to each stream. Selected MPs (Table 3) were dosed at concentrations generally between 0.2 and $2 \mu \mathrm{g} \mathrm{L} \mathrm{L}^{-1}$ into the feed via glass ampoules and/or pipetted from solutions of the compounds dissolved in water/acetone, the latter adding up $15 \%$ to the organic carbon but assumed to be inert under the AOP operating conditions employed, based on previous studies (Hernandez et al., 2002). All MPs were of an analytical grade and provided by Sigma Aldrich, with the exception of the EDC compounds (E1,E2 and EE2) which were from QMX Laboratories (Essex, UK).

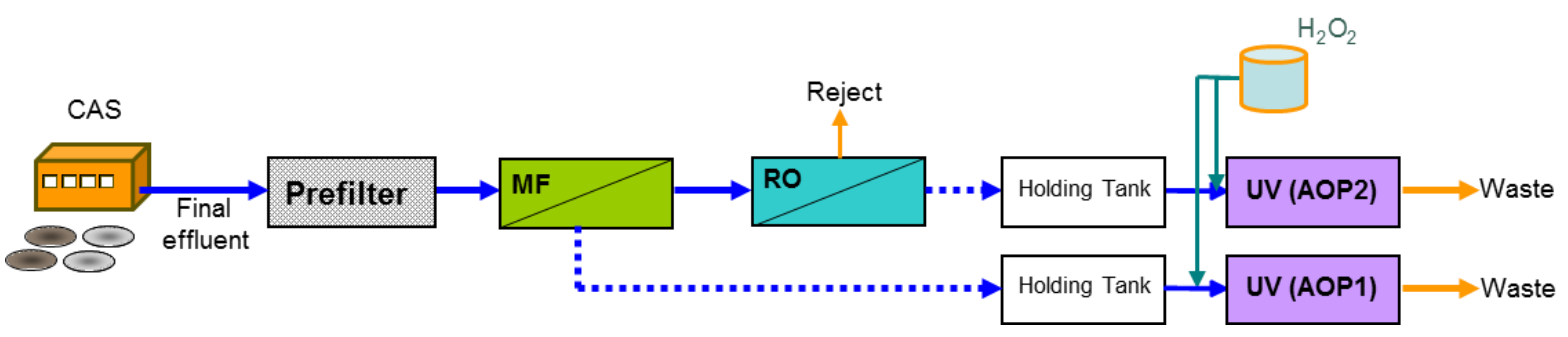

Figure 1. Pilot plant schematic

\subsection{Experimental procedure}

Feed water quality was varied by testing either the MF, RO or an equal blend of the two permeate streams (Table 1). MPs were then dosed at concentrations based on those typically arising in secondary wastewater, as identified in the literature (Lundstrom et al., 2010; Martin Ruel et al., 2011) and regulatory guidelines (WSR, 2010), or else constrained by their limit of detection as advised by the laboratory (Thames Water Analytical Laboratories, Reading) to allow \% removal values to be accurately calculated. Operating conditions for each AOP stream (Table 2) were determined from the optimum UV lamp input power and $\mathrm{H}_{2} \mathrm{O}_{2}$ dose for each AOP stream for efficient removal of target MPs to the required log reduction, based on outcomes of initial scoping trials.

Chemicals were prepared to a required concentration and dosed directly into a $1 \mathrm{~m}^{3}$ storage tank, fitted with a submersible mixing pump, for holding the MF/RO permeate or blend. This feedwater was pumped to the UV unit with in-line $\mathrm{H}_{2} \mathrm{O}_{2}$ dosing upstream of a static mixer at flow rates of 1-3 $\mathrm{m}^{3} \mathrm{~h}^{-1}$, providing residence times of 120-180 s. An experimental test comprised feed solution mixing for 20 minutes, to ensure a homogeneous solution, followed 
by once-through AOP treatment for 20 minutes. Sampling of the outlet stream was timed to allow for the above residence time.

A daily $5 \mathrm{wt} \%$ citric acid CIP was performed on AOP1 to minimise sleeve fouling. The reactor was flushed through with the normal permeate stream following each experiment. Experiments were conducted separately for NDMA and MA to ensure no competition between the two sets of reactions; the EDCs, pesticides and herbicides were combined in the same bulk feedwater solution as applied in other studies (MWH, 2007). Duplicate samples for each MP compound were taken from the feed tank and triplicate samples collected postAOP at 5, 10, and 15 minute intervals. Tests were repeated for any apparent anomalies.

Sampling and analysis was conducted for MPs along with standard sanitary determinants. All compounds were analysed by Thames Water Laboratories (Reading, UK) using standard methods (APHA, 2005). EDCs, atrazine and terbutryn were analysed by liquid chromatography with mass spectrophotometric detection (LS-MS-MS), ion chromatography (IC) was used to analyse NDMA, whilst the remaining herbicides and MA were analysed by gas chromatography (GC-MS).

Table 1: Mean and standard deviation values of feedwater quality parameters for each stream.

\begin{tabular}{|c|c|c|c|c|}
\hline Compound & Unit & MF permeate & RO permeate & MF/RO Blend \\
\hline Alkalinity as $\mathrm{CaCO}_{3}$ & $\mathrm{mg} \cdot \mathrm{L}^{-1}$ & $212 \pm 12.4$ & $<16$ & - \\
\hline Conductivity & $\mu \mathrm{S} \mathrm{cm}^{-1}$ & $1061 \pm 15.3$ & $20.8 \pm 2.35$ & _ \\
\hline $\mathrm{pH}$ & & $7.3 \pm 0.07$ & $5.5 \pm 0.05$ & $7.14 \pm 0.14$ \\
\hline Hardness Total as $\mathrm{CaCO}_{3}$ & $\mathrm{mg} \cdot \mathrm{L}^{-1}$ & $332.9 \pm 16.7$ & $<29$ & - \\
\hline Total Organic Carbon (TOC) & $\mathrm{mg} \cdot \mathrm{L}^{-1}$ & $7.7 \pm 0.73$ & $0.2 \pm 0.17$ & $4.85 \pm 0.11$ \\
\hline Turbidity & NTU & $0.14 \pm 0.21$ & $0.08 \pm 0.02$ & - \\
\hline $\mathrm{UV}$ absorbance at $254 \mathrm{~nm}\left(\mathrm{UV}_{254}\right)$ & $\mathrm{cm}^{-1}$ & $0.18 \pm 0.002$ & $0.001 \pm 0.002$ & $0.11 \pm 0.008$ \\
\hline UV transmittance (UVT) & & $66 \pm 0.82$ & $98.8 \pm 0.41$ & $76.2 \pm 1.44$ \\
\hline Specific UV Absorbance (SUVA) & L.mg ${ }^{-1} . m$. & 2.34 & 0.5 & 2.26 \\
\hline
\end{tabular}

Table 2: Operational conditions for the AOP spiking trials

\begin{tabular}{l|ll}
\hline Parameter & AOP1 & AOP2 \\
\hline Feed water & MF filtrate & RO permeate \\
Lamp power set-point $(\%)$ & $100 \%$ & $60 \%$ \\
Power Input P / Optimal Range $(\mathrm{kWh})$ & $2.82 / 1.68-2.82$ & $1.78 / 1.78-2.98$ \\
Lamp Life $(\mathrm{h})$ & 1380 & 1100 \\
Peroxide dose/ Optimal Range $\left(\mathrm{mg} \mathrm{L}^{-1}\right)$ & $16 / 6-20$ & $3 / 1-3$ \\
Treatment capacity $\left(\mathrm{m}^{3} \mathrm{~h}^{-1}\right)$ & 3 & 3 \\
Reactor volume $\left(\mathrm{m}^{3}\right)$ & 0.098 & 0.098 \\
Theoretical contact time $(\mathrm{s})$ & approx. 120 & approx. 120 \\
\hline
\end{tabular}

The optimisation trials were based on MA, the most recalcitrant of the micropollutants examined. Three equally-spaced $\mathrm{H}_{2} \mathrm{O}_{2}$ doses and power inputs were employed with each stream (MF permeate, RO permeate, and blend) and correlated with MA removal (Table 3). This approach allowed Box-Behnken design (Box and Behnken, 1960; Raffin et al, 2011) to be applied, reducing the number of experiments for a three-level, three-parameter study from 27 for a $3^{\mathrm{n}}$ factorial design to 15 . 
Table 3: Parameters and their levels, Box-Behnken analysis

\begin{tabular}{l|ll}
\hline Param. \# & Parameters & Levels \\
\hline $\mathrm{X}_{1}$ & $\mathrm{H}_{2} \mathrm{O}_{2}$ dose $\left(\mathrm{mg} \mathrm{L}^{-1}\right)$ & $3,9.5,16$ \\
$\mathrm{X}_{2}$ & $\mathrm{UV}-\mathrm{T}(\%)$ & $65,82,98$ \\
$\mathrm{X}_{3}$ & Power input $(\mathrm{kWh})$ & $1.68,2.33,2.98$ \\
\hline
\end{tabular}

Evaluated efficiency values were based on electrical energy per order $\left(E_{E O}\right)$, as used by previous workers studying similar AOP systems (Bolton et al, 2001), along with specific energy demand $\left(E_{D}\right)$ to benchmark against other advanced technologies such as RO. $E_{E O}$ is defined by these authors as the electrical energy in $\mathrm{kWh}$ required to reduce the concentration of a contaminant by one order of magnitude in $1 \mathrm{~m}^{3}$.

$$
E_{E O}=P /\left(Q \log \left(\mathrm{c}_{\mathrm{i}} / \mathrm{c}_{\mathrm{f}}\right)\right)
$$

where $P$ is the electrical power $(\mathrm{kW})$ of the UV system, $Q$ is the flow rate $\left(\mathrm{m}^{3} / \mathrm{h}\right)$, and $C_{i}$ and $C_{f}$ the initial and final contaminant concentrations $\left(\mathrm{mg} \mathrm{L}^{-1}\right)$. Specific energy demand $\left(E_{D}\right)$, the electrical energy $(\mathrm{kWh})$ consumed per unit volume of water treated, was also calculated so as to provide a further benchmark in cases where $90 \%$ (or $1 \mathrm{log}$ ) reduction was not achieved:

$$
E_{D}=P / Q
$$

\section{Results and discussion}

\subsection{MP removal}

Measured concentrations (Table 4) revealed all the MPs studied to be removed by at least $97 \%$ when applying AOP to the RO permeate at an $\mathrm{H}_{2} \mathrm{O}_{2}$ dose of $3 \mathrm{mg} \mathrm{L}^{-1}$ and an $E_{D}$ of 0.62 $\mathrm{kWh} \mathrm{m}^{-3}$. In contrast, application to the MF permeate was much less effective in removing herbicides and pesticides generally, and MA in particular. Even at very high $\mathrm{H}_{2} \mathrm{O}_{2}$ doses of $16 \mathrm{mg} \mathrm{L}^{-1}$ with $E_{D}$ levels of $0.93 \mathrm{kWh} \mathrm{m}^{-3}$, MA removal remained below $50 \%$. Estrogenic substances (E1, E2 and EE2), on the other hand, were readily degraded (>99\%) in both streams. These observations are consistent with those reported elsewhere (IJpelaar et al, 2010; Rosenfeldt and Linden, 2004) for UV doses of $600-1000 \mathrm{~mJ} \mathrm{~cm} \mathrm{~cm}^{-2}$ and $\mathrm{H}_{2} \mathrm{O}_{2}$ concentrations of $10-15 \mathrm{mg} \mathrm{L}^{-1}$; >90\% removal of these compounds was reported based on bench-scale $\mathrm{UV} / \mathrm{H}_{2} \mathrm{O}_{2}$.

Differences in measured removal between the two permeate streams reflect those in UV transmittance (UVT) (Table 1), which is near total for the RO permeate compared with only $65 \%$ for the MF permeate. Higher doses of $\mathrm{H}_{2} \mathrm{O}_{2}$ in AOP1 were thus needed to compensate for the lower photon absorption efficiency (Tuhkanen, 2004). Moreover, competition for ${ }^{\circ} \mathrm{OH}$ was greater in the MF stream due to significantly higher levels of scavengers (organic carbon, chloride and bicarbonate/carbonate ions), manifested as a higher $\mathrm{E}_{\mathrm{EO}}$ value. $\mathrm{pH}$ would also be expected to influence oxidation efficiency since increasing $\mathrm{pH}$ converts more of the dissolved $\mathrm{CO}_{2}$ to bicarbonate and so promotes scavenging (Liao and Gurol, 1995). However, reducing the MF permeate $\mathrm{pH}$ from $\sim 7.2$ to 5.5 was found to produce only a marginal increase $(<10 \%)$ in metaldehyde removal. Other contributory factors, such as scaling/fouling of the lamp sleeves and other MF permeate water quality parameters (Stefan, 2004), would also be expected to reduce UV intensity and so AOP efficacy. 
Table 4: Micro-pollutant removal results for Post MF and RO streams under optimum process conditions (power input and $\mathrm{H}_{2} \mathrm{O}_{2}$ dose).

\begin{tabular}{|c|c|c|c|c|c|c|c|c|}
\hline Stream & $\begin{array}{l}\text { Classifi- } \\
\text { cation }\end{array}$ & Compound & $\begin{array}{c}\text { Inlet Conc. } \\
\left(\mu \mathrm{g} . \mathrm{I}^{-1}\right)\end{array}$ & $\begin{array}{c}\% \\
\text { removal }\end{array}$ & $\begin{array}{l}\text { Log } \\
\text { reduction }\end{array}$ & $\begin{array}{l}\text { UV Dose } \\
\left(\mathrm{mJ} \mathrm{cm}^{-2}\right)\end{array}$ & $\begin{array}{c}\text { Ed }(k W h \\
\left.m^{-3}\right)\end{array}$ & $\begin{array}{c}\text { EEO } \\
\left(\mathrm{kWh} \mathrm{m}^{-3}\right)\end{array}$ \\
\hline \multirow{10}{*}{$\begin{array}{c}\text { AOP 1 } \\
\text { (post- } \\
\text { MF) }\end{array}$} & EDC & E1 Estrone & 0.2 & 99 & 2.16 & 695 & 0.95 & 0.44 \\
\hline & $\mathrm{EDC}$ & E2 17- $\beta$ Estradiol & 0.2 & 99 & 2.11 & 695 & 0.95 & 0.45 \\
\hline & EDC & $\begin{array}{l}\text { EE2 } \alpha \text { Ethinyl } \\
\text { Estradiol }\end{array}$ & 0.2 & 99 & 2.32 & 695 & 0.95 & 0.41 \\
\hline & Herbicide & $2,4-\mathrm{D}$ & 1 & 89 & 0.98 & 727 & 0.95 & - \\
\hline & Herbicide & Mecoprop & 1 & 98 & 1.61 & 727 & 0.95 & 0.59 \\
\hline & Herbicide & $2,45-\mathrm{T}$ & 1 & 85 & 0.83 & 727 & 0.95 & - \\
\hline & Pesticide & Atrazine & 2 & 88 & 0.92 & 713 & 0.95 & - \\
\hline & Pesticide & Terbutryn & 2 & 96 & 1.38 & 713 & 0.95 & 0.69 \\
\hline & Volatile & NDMA & 0.2 & 98 & 1.62 & 678 & 0.95 & 0.59 \\
\hline & Pesticide & Metaldehyde & 2 & 45 & 0.26 & 739 & 0.93 & - \\
\hline \multirow{10}{*}{$\begin{array}{c}\text { AOP } 2 \\
\text { (post- } \\
\text { RO) }\end{array}$} & EDC & E1 Estrone & 0.2 & 99 & 3.25 & 2026 & 0.62 & 0.19 \\
\hline & EDC & E2 $17-\beta$ Estradiol & 0.2 & 99 & 3.21 & 2026 & 0.62 & 0.19 \\
\hline & EDC & $\begin{array}{l}\text { EE2 } \alpha \text { Ethinyl } \\
\text { Estradiol }\end{array}$ & 0.2 & 99 & 3.18 & 2026 & 0.62 & 0.19 \\
\hline & Herbicide & $2,4-\mathrm{D}$ & 1 & 99 & 2.72 & 1825 & 0.62 & 0.23 \\
\hline & Herbicide & Mecoprop & 1 & 99 & 2.60 & 1825 & 0.62 & 0.24 \\
\hline & Herbicide & $2,45-\mathrm{T}$ & 1 & 99 & 2.70 & 1825 & 0.62 & 0.23 \\
\hline & Pesticide & Atrazine & 2 & 98 & 1.62 & 1775 & 0.62 & 0.39 \\
\hline & Pesticide & Terbutryn & 2 & 99 & 2.40 & 1775 & 0.62 & 0.26 \\
\hline & DBP & NDMA & 0.2 & 99 & 2.39 & 1845 & 0.62 & 0.26 \\
\hline & Pesticide & Metaldehyde & 0.2 & 98 & 1.70 & 2003 & 0.62 & 0.36 \\
\hline
\end{tabular}

\subsection{Metaldehyde removal}

Tests conducted on MA specifically demonstrated increased removal with increasing UV and $\mathrm{H}_{2} \mathrm{O}_{2}$ dose (Fig. 2). However, metaldehyde was only significantly removed when the AOP was applied to the RO permeate, since the received UV dose was around five times greater than that for the MF permeate. Removal exceeded $95 \%$ at a peroxide dose of $2 \mathrm{mg} \mathrm{L}^{-1}$ and an $E_{D}$ of $\sim 0.7 \mathrm{kWh} \mathrm{m}^{-3}$ (Fig. 3). Other studies have reported similar removal rates (Autin et al., 2012), citing lower UV fluences of $600 \mathrm{~mJ} \mathrm{~cm}^{-2}$ for laboratory grade water, but at considerably higher $\mathrm{H}_{2} \mathrm{O}_{2}$ doses of $272 \mathrm{mg} \mathrm{L}^{-1}$. For MF permeate, energy inputs above 0.75 $\mathrm{kWh} \mathrm{m}^{-3}$ achieved no more than $40 \%$ removal (Fig. 3). Removal from MF permeate at a UV dose of around $460 \mathrm{~mJ} \mathrm{~cm}^{-2}$ ranged from 3 to $45 \%$ according to $\mathrm{H}_{2} \mathrm{O}_{2}$ concentration (Fig. 4).

Removal is, however, improved by $\mathrm{H}_{2} \mathrm{O}_{2}$ addition, particularly in poorer water quality. An increased $\mathrm{H}_{2} \mathrm{O}_{2}$ concentration may thus further increase degradation, provided the peroxide itself does not scavenge $\mathrm{OH}$ at these elevated concentrations as suggested by other authors (Galbraith et al, 1992). The relationship between UV dose and energy demand for each stream (Figure 5) indicates that higher UV doses are only attainable at the upper limits of UV transmittance at comparable energy demand. UV doses above $2000 \mathrm{~mJ} \mathrm{~cm}^{-2}$ with at $>2 \mathrm{mg} \mathrm{L}^{-}$

${ }^{1} \mathrm{H}_{2} \mathrm{O}_{2}$ appear sufficient to attain $>90 \%$ removal of MA. 


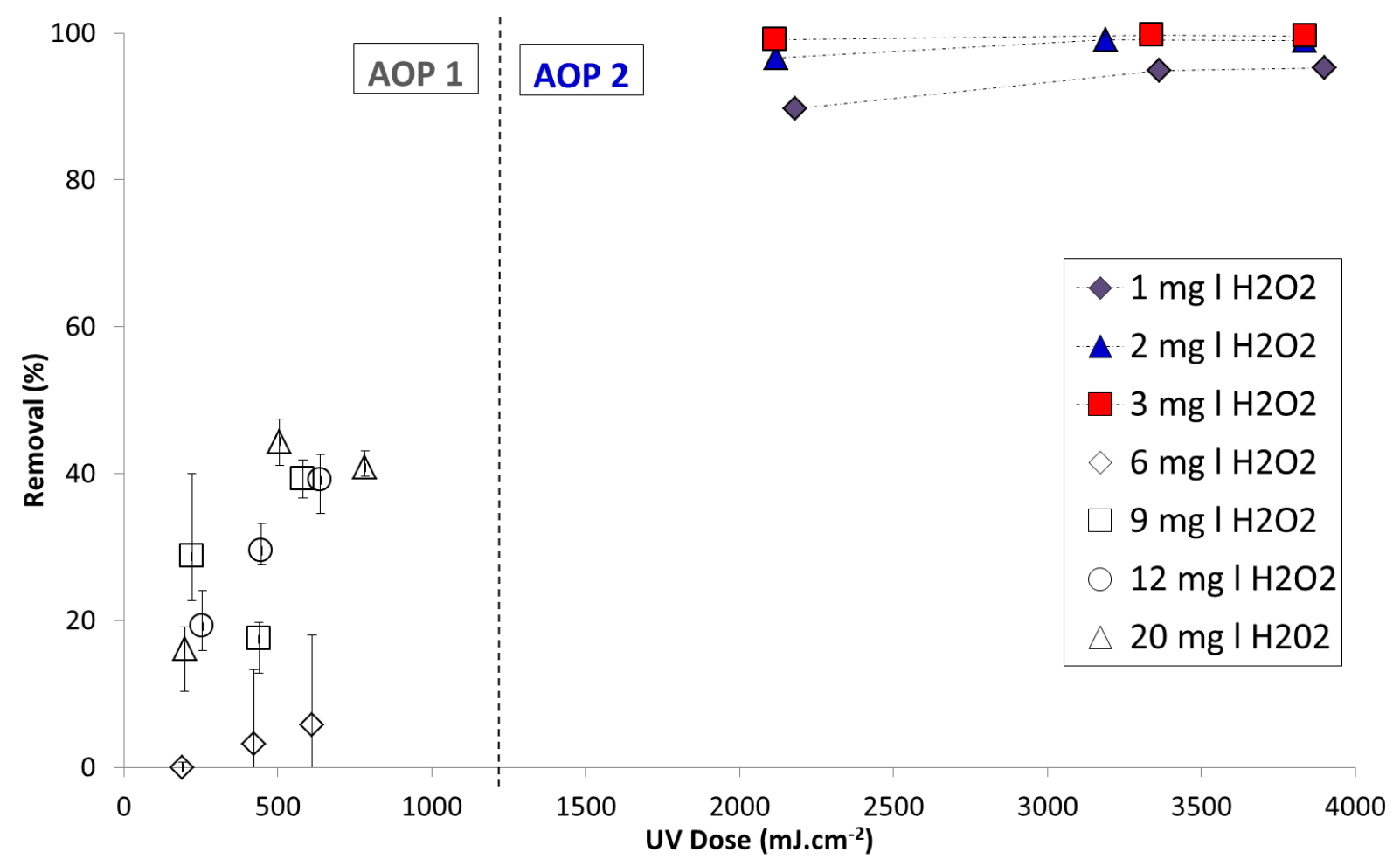

Figure 2. Effect of $\mathrm{UV}$ and $\mathrm{H}_{2} \mathrm{O}_{2}$ dose on the removal of metaldehyde from MF permeate (AOP1) and RO permeate (AOP2).

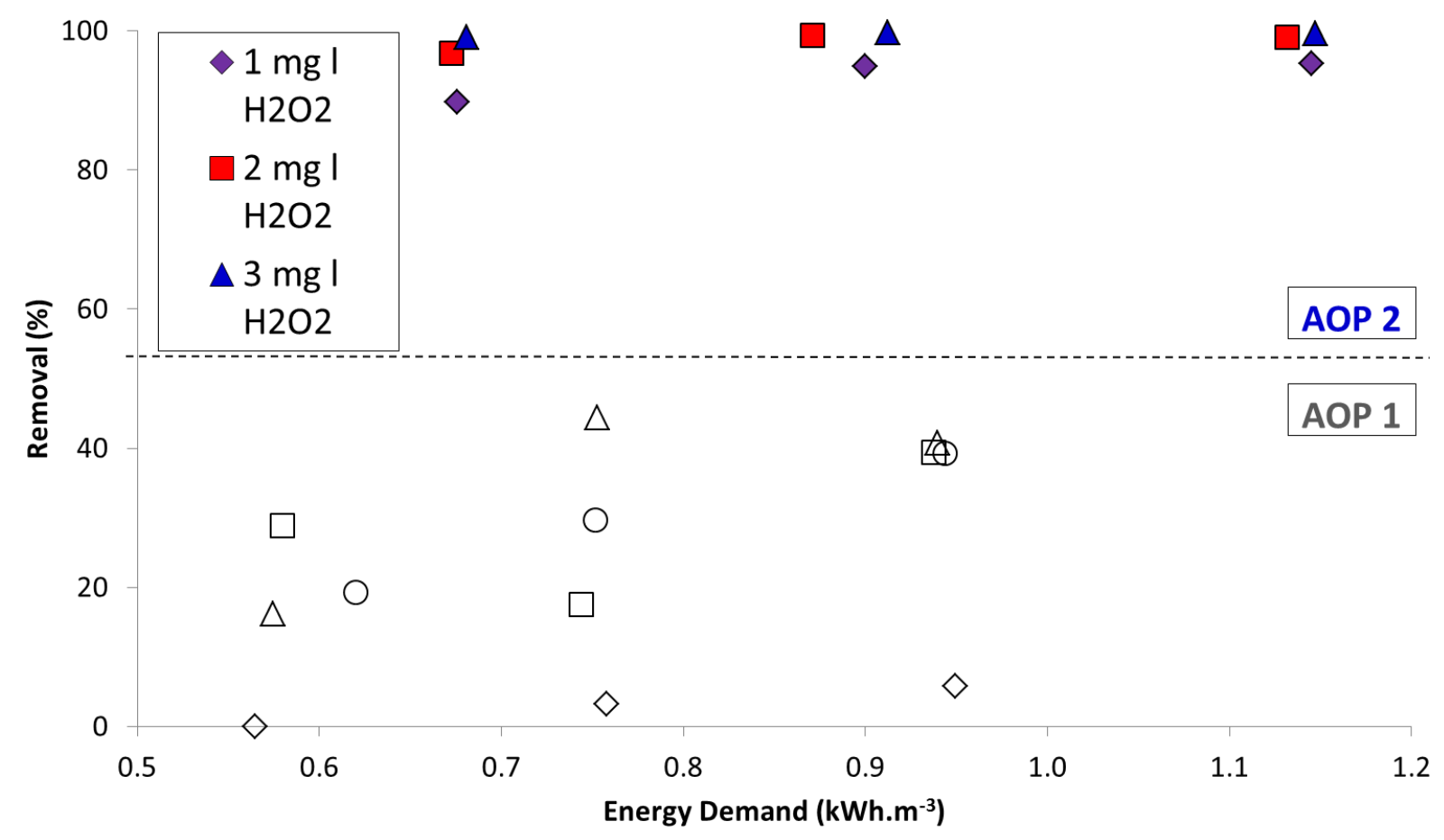

Figure 3. $\mathrm{E}_{\mathrm{D}}$ data for metaldehyde degradation in $\mathrm{MF}$ (AOP1) and $\mathrm{RO}$ (AOP2) permeate as a function of $\mathrm{H}_{2} \mathrm{O}_{2}$ dose. 


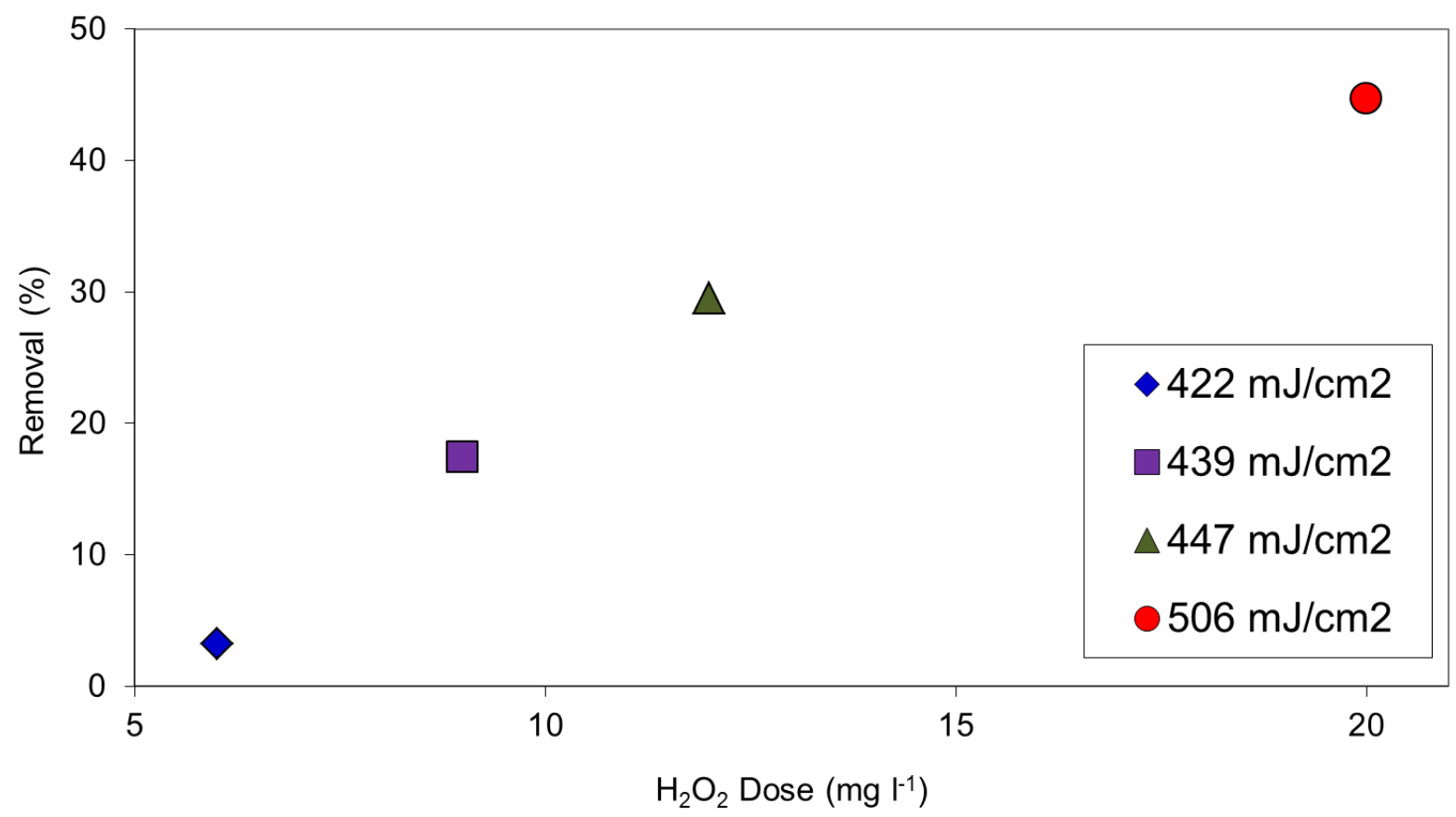

Figure 4. Metaldehyde removal from MF permeate as a function of $\mathrm{H}_{2} \mathrm{O}_{2}$ dose at $\mathrm{UV}$ dose $422-506 \mathrm{~mJ} \mathrm{~cm}^{-2}$ and a power of $2.25 \mathrm{~kW}$.

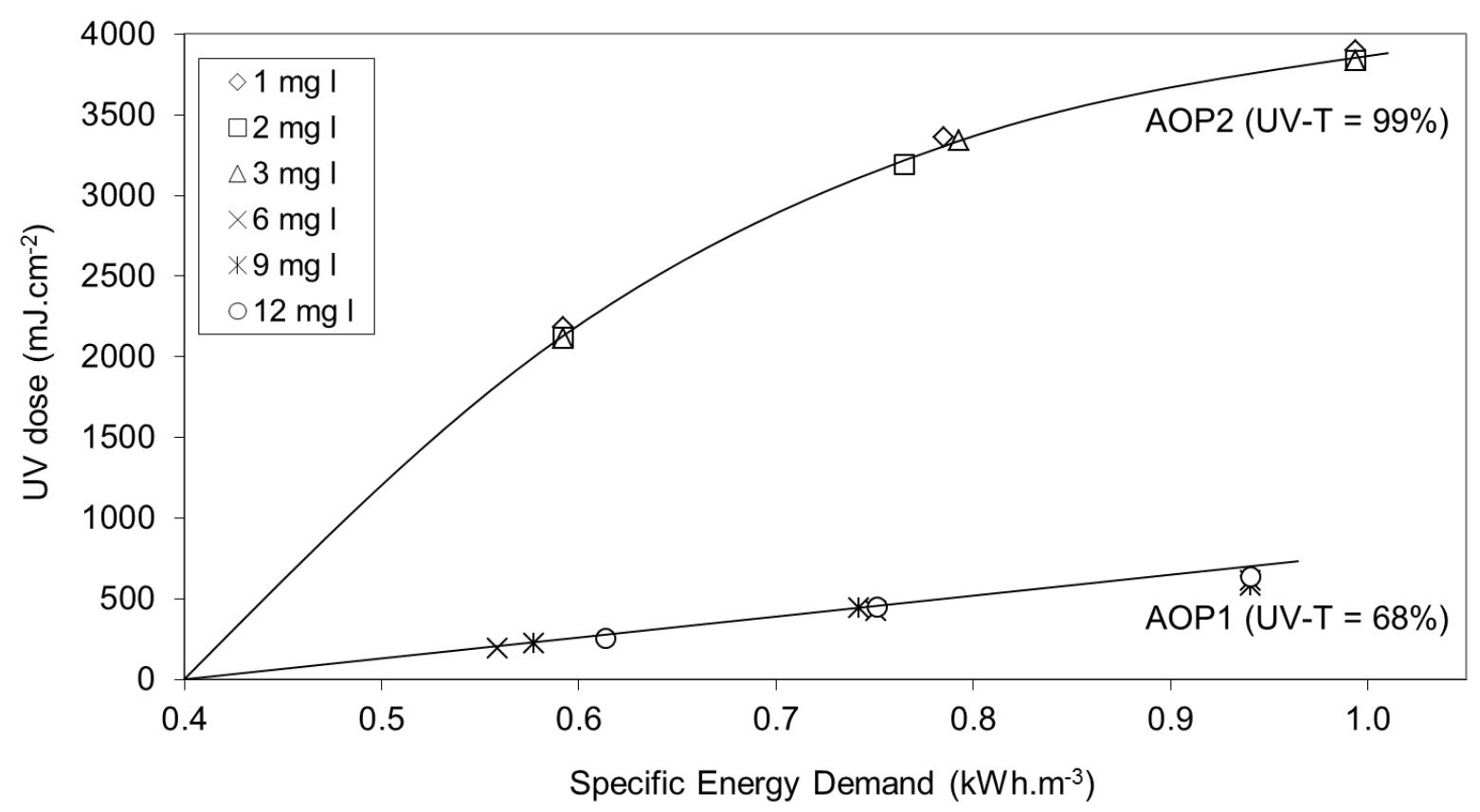

Figure 5. Influence of UVT on the UV dose output as a function of energy input at various $\mathrm{H}_{2} \mathrm{O}_{2}$ concentrations $\left(1-20 \mathrm{mg} \mathrm{L}^{-1}\right)$ in streams AOP 1 and 2.

\subsection{Effect of residence time}

Figure 6 shows the influence of retention time (RT) on MA removal from the MF permeate. Removal appears to increase from $40 \%$ to $>75 \%$ on trebling RT from around two minutes, depending upon the power applied. UV intensity levels were increased 1.5-2 fold at extended 
RTs, relative to the lamp power input $\left(3.1 \mathrm{~mW} \mathrm{~cm}^{-2}\right.$ at $1.67 \mathrm{~kW} ; 8.9 \mathrm{~mW} \mathrm{~cm}^{-2}$ at $\left.2.82 \mathrm{~kW}\right)$. This probably results from improved $\mathrm{UV}_{254}$ transmittance (Stefan, 2004), which increased after AOP treatment in all experiments at higher UV doses in particular - presumably as a result of the rupturing of conjugated bonds in the NOM molecular structure (Toor and Mohseni, 2007).

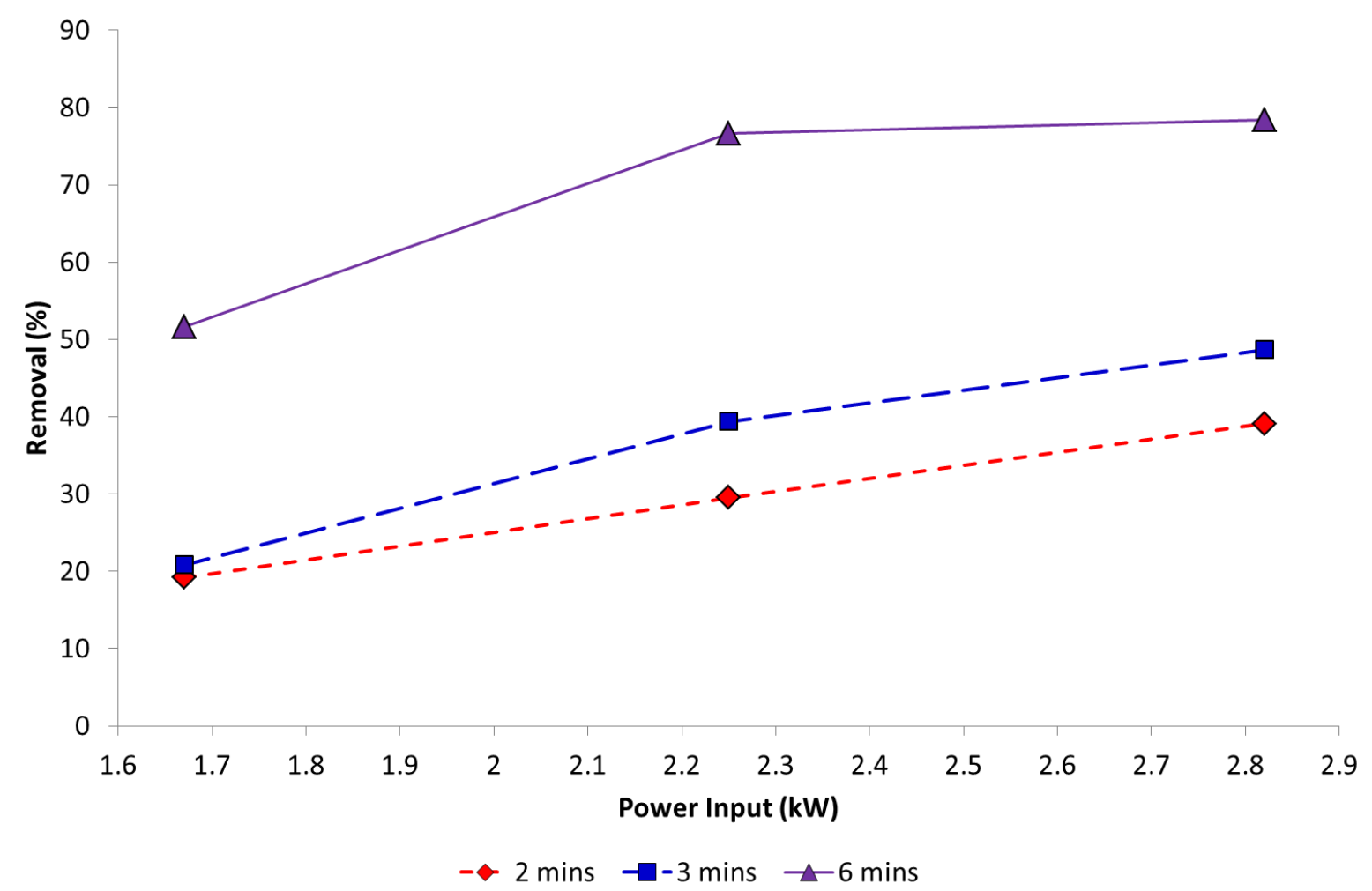

Figure 6. Influence of residence time on the degradation of metaldehyde in MF permeate as a function of power input, $16 \mathrm{mg} \mathrm{L}^{-1} \mathrm{H}_{2} \mathrm{O}_{2}$.

\subsection{Effect of UV transmittance (UVT)}

The influence of UVT was quantified through blending of the MF and RO permeate streams in conjunction with power input and peroxide dose using a Box-Behnken design (BBD) based on the levels indicated in Table 3. Regression analysis revealed $\mathrm{UVT}_{254}$ and $\mathrm{H}_{2} \mathrm{O}_{2}$ dose (C) to be the only significantly influential parameters on metaldehyde removal ( $p$-value $<0.05$ for the linear coefficient in both cases), with power input having no significant impact (pvalue 0.18$)$ due to the limited range applied $(1.66-2.82 \mathrm{~kW})$. The overall relationship between \% metaldehyde passage (P) and peroxide concentration and UV transmittance (Fig. 7) from multiple linear regression analysis $\left(R^{2}=0.96\right)$ :

$$
\mathrm{P}=671-16.2 \mathrm{C}-11.44 \mathrm{UVT}+0.271 \mathrm{C}^{2}+0.0497(\mathrm{UVT})^{2}+0.1056 \mathrm{C} \mathrm{UVT}
$$

The analysis indicates the extreme sensitivity of metaldehyde passage ( 1 - removal) to UVT, with passage at a dose of $8 \mathrm{mg} \mathrm{L}^{-1} \mathrm{H}_{2} \mathrm{O}_{2}$ ranging from $80 \%$ down to $8 \%$ on increasing the UVT from 65 to $90 \%$. UV transmittance thus appears to be a significant parameter in determining the economic viability of AOP treatment for MA removal. 


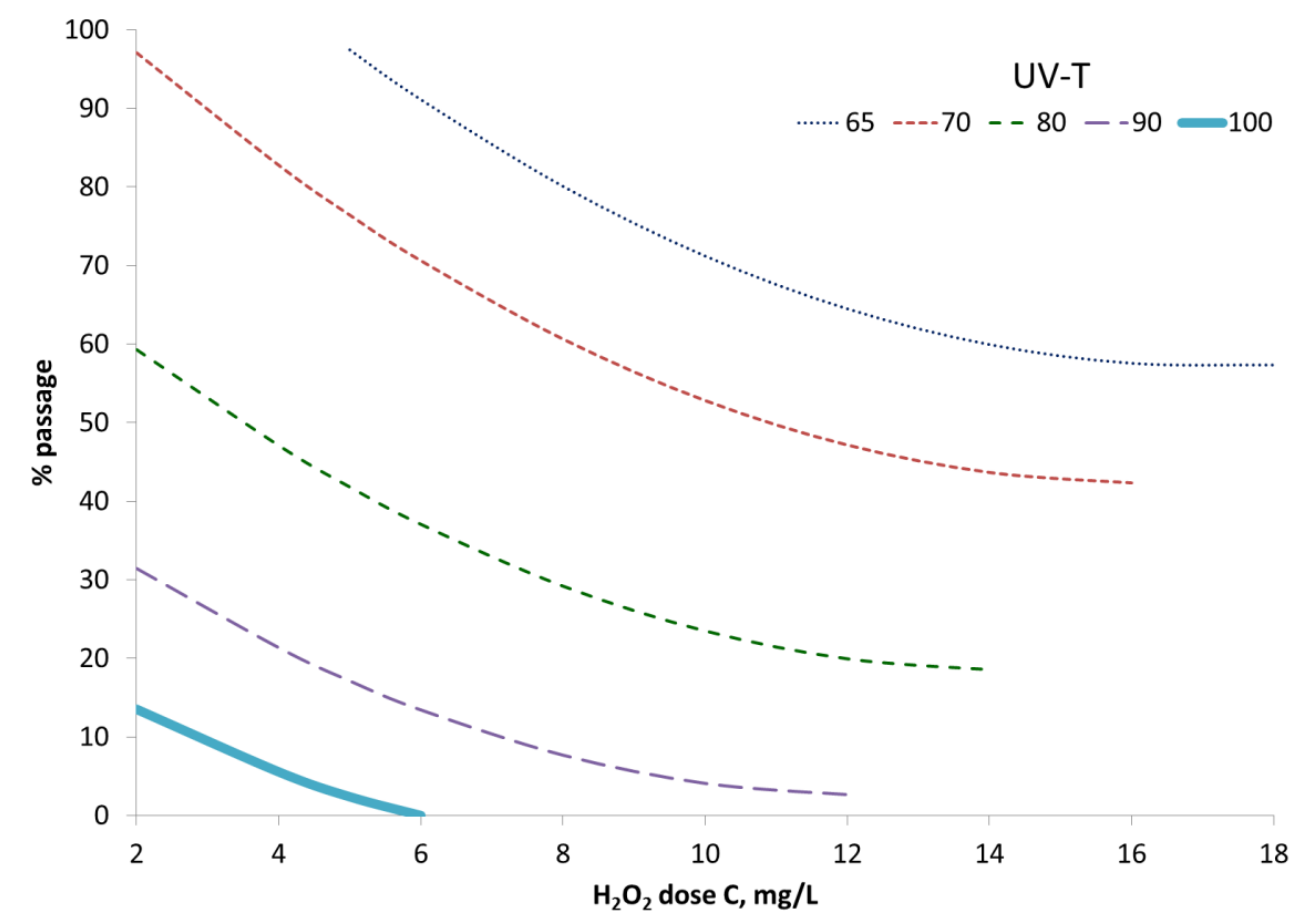

Figure 7. Effect of UVT on metaldehyde passage (100-\%removal) as a function of UVT and $\mathrm{H}_{2} \mathrm{O}_{2}$ concentration, according to BBD analysis, $1.68-2.98 \mathrm{~kW}$ power input (from Equation 3)

\subsection{Operating expenditure (OPEX)}

The operating cost of applying a $\mathrm{UV} / \mathrm{H}_{2} \mathrm{O}_{2}$ AOP for MP removal is determined primarily by:

- the energy demand $E_{D}$ of the UV device,

- the hydrogen peroxide demand, and

- the replacement frequency of critical, high-cost components.

The first two of these are defined by the outputs from Equation 3 (Figure 7), which permits computation of OPEX for water qualities pertaining to the MF and RO permeate based on the test conditions employed (Table 5). It is of interest to extend the OPEX calculation to include both other OPEX components and alternative treatment options for attaining a nominal target removal.

Table 5: AOP treatment conditions and associated OPEX relating to test conditions employed in the current study (MF and MF-RO pretreatment).

\begin{tabular}{l|cc}
\hline Parameter & MF-AOP & MF-RO-AOP \\
\hline$E_{D}$, kWh.m & \\
UV dose, mJ cm & & 0.50 \\
$\%$ MA removal & 2.17 & 2181 \\
$\mathrm{H}_{2} \mathrm{O}_{2}$ dose, $\mathrm{mg} \mathrm{L}^{-1}$ & 2600 & 80 \\
\hline $\mathrm{OPEX}^{*} £ \mathrm{~m}^{3}$ & 16 & 1 \\
Energy & & \\
Chemicals & 0.241 & 0.072 \\
Maintenance & 0.033 & 0.002 \\
TOTAL & 0.099 & 0.099 \\
\hline
\end{tabular}

*Electricity cost $0.11 £ \mathrm{kWh}^{-1}$ (Energy EU, 2012); 35\% w/v $\mathrm{H}_{2} \mathrm{O}_{2} 0.59 £ \mathrm{~L}^{-1}$ (Supplier); Pump rating $0.25 \mathrm{~kW} ; \mathrm{H}_{2} \mathrm{O}_{2}$ pump rating, $0.015 \mathrm{~kW}$; Lamp life $9000 \mathrm{~h}$; citric acid CIP frequency $26 \mathrm{y}^{-1}$; citric acid CIP concentration $2.5 \mathrm{~g} \mathrm{~L}^{-1}$ 
A recent study of municipal wastewater reuse based on the same plant as that employed in the current study provided projected costs of $£ 0.069-0.084 \mathrm{~m}^{-3}$ for the MF process and £0.19$0.23 \mathrm{~m}^{-3}$ for the complete MF-RO process for flows of 25-100 MLD (Raffin, 2012). This compares with costs of $£ 0.25-0.26 \mathrm{~m}^{-3}$ calculated for a similar MF-RO process (Garcia et al, 2013) for the same range of flow. The $62 \%$ figure for the mean proportion of the MF-RO OPEX attributed to the RO stage is very similar to the same parameter for the proportion of the energy demand (58\%) averaged across six MF-RO municipal wastewater reuse plants worldwide (Raffin et al, 2013).

Since OPEX is primarily a function of the UVT, it is appropriate to consider the option of activated carbon $(\mathrm{AC})$ for removing TOC which represents the main contributor to impaired UV transmittance. Recent trials, again based on the same plant (Hatt et al, 2013), have explored the options of employing powdered AC upstream of the MF, as well as downstream granular media beds (GAC). The outcomes suggest that either of these options can achieve $60-70 \%$ removal of $\mathrm{UVT}_{254}$ from secondary wastewater, at a $\sim 1500$ bed volume capacity in the case of GAC. Based on a projected regeneration cost of $£ 0.31-0.44$ per $\mathrm{kg}$ (Supplier, 2013) and assuming a 5-10\% loss of GAC per regeneration, this provides a GAC cost of $£ 0.09-0.16$ per $\mathrm{m}^{-3}$ of water treated.

The AOP $E_{D}$ and peroxide demand values computed from Equation 3 associated with the treatment of water from MF, MF-AC, and MF-RO were determined from the water quality correlations based on $>75 \%$ metaldehyde removal (Table 6). Combining the associated OPEX of these demand data (based on the assumptions listed in Table 5) allows the OPEX of the AOP stage to be determined for each of these streams. These can then be combined with the costs relating to the other unit operations (Table 7) to generate total OPEX values of the key candidate process treatment schemes (Figure 8), which exclude both labour and disposal costs but are otherwise based on similar conditions of feedwater quality (secondary municipal effluent).

Table 6: Calculated OPEX for AOP process within three treatment schemes for $>75 \%$ metaldehyde removal.

\begin{tabular}{l|ccc}
\hline Parameter & MF-AOP & MF-AC-AOP & MF-RO-AOP \\
\hline $\mathrm{E}_{\mathrm{D}}, \mathrm{kWh} . \mathrm{m}^{-3}$ & 2.17 & 0.77 & 0.50 \\
$\mathrm{UV}$ dose, $\mathrm{mJ} \mathrm{cm}^{2}$ & 2600 & 2196 & 2181 \\
$\%$ removal & 77 & 82 & 80 \\
$\mathrm{H}_{2} \mathrm{O}_{2}$ dose, $\mathrm{mg} \mathrm{L}^{-1}$ & 16 & 5 & 1 \\
\hline
\end{tabular}

Table 7: Comparable unit process OPEX, $£ \mathrm{~m}^{-3}$

\begin{tabular}{l|ccl}
\hline Process & \multicolumn{1}{|c}{ Min } & Max & Source \\
\hline MF & 0.069 & 0.084 & Raffin (2012) \\
Total, MF-RO & 0.19 & 0.228 & Raffin (2012) \\
& 0.25 & 0.26 & Garcia et al (2013) \\
\%RO of total & 0.62 & 0.62 & Raffin (2012) \\
AOP, post MF & 0.373 & & James et al (this study) \\
AOP, post RO & 0.176 & & James et al (this study) \\
AOP, post AC & 0.199 & & James et al (this study) \\
GAC & 0.09 & 0.16 & Hatt et al (2013) \\
\hline
\end{tabular}


The OPEX data (Figure 8) indicate the MF-RO-AOP process to be slightly lower in cost (by 20\%) than either of the two other enhanced treatment process options (MF-AOP or MF-ACAOP), whose OPEX values are comparable. However, the MF-RO-AOP option incurs an additional capital cost from the RO process stage, and relies on an appropriate route for disposal of the RO concentrate stream. All three options are considerably more costly, by between 70 and 190\%, than the "standard" two-stage MF-RO process.

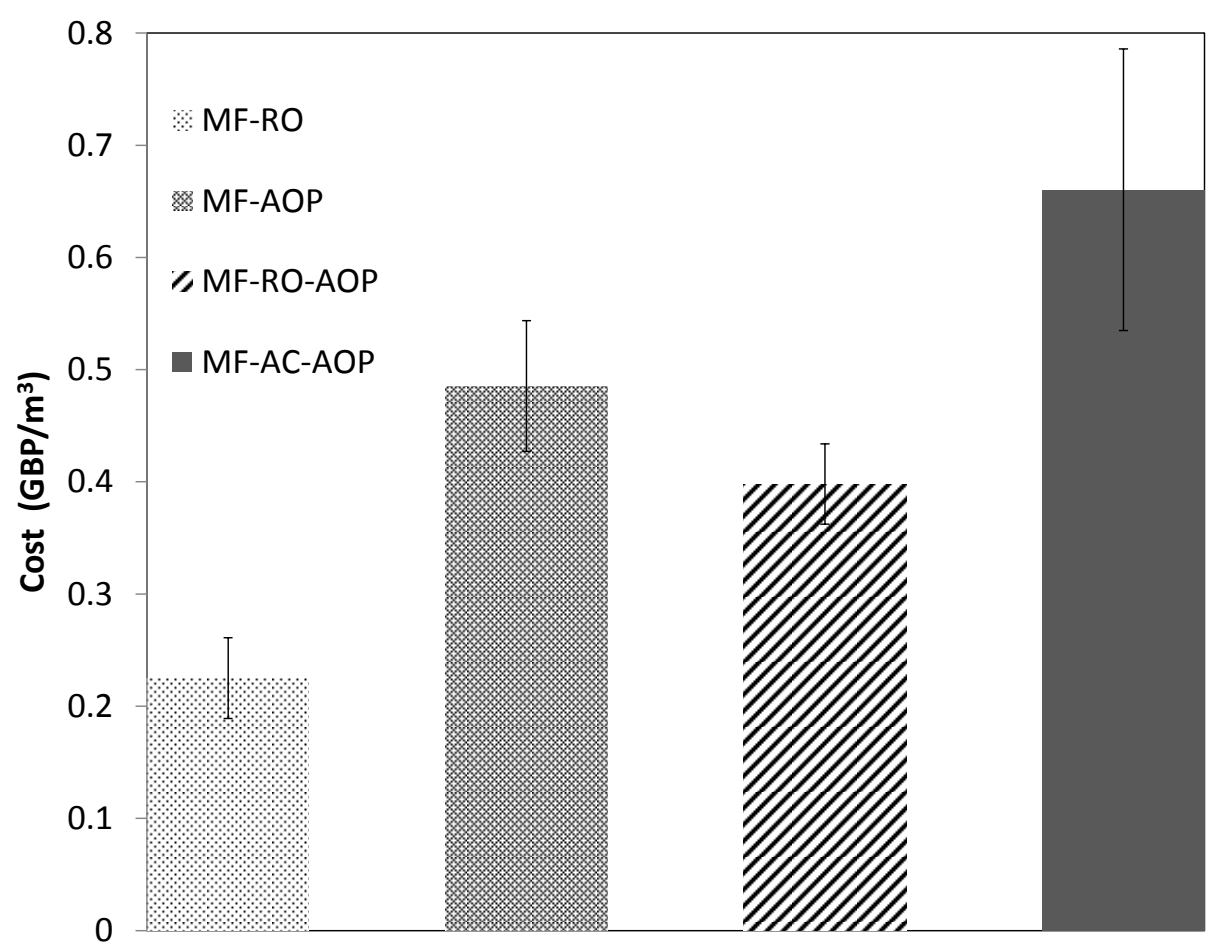

Figure 8. Projected OPEX values of four treatment schemes, based on 77-90\% removal of metaldehyde from secondary municipal wastewater.

\section{Conclusions}

An extensive pilot-scale study of the efficacy of an advanced oxidation $\mathrm{UV}-\mathrm{H}_{2} \mathrm{O}_{2}$ process for micropollutant (MP) removal has been conducted. Results indicate feedwater UV transmittance as being pivotal to the process economic viability, since this factor dramatically impacts on energy and/or oxidative chemical demand. Notwithstanding this, tests indicated all MPs other than metaldehyde and trihalomethanes to be removed by at least $85 \%$ by the AOP process when employed downstream of a microfilter (MF), with the estrogenic substances being more than $99 \%$ removed down to levels of $\sim 1 \mathrm{ng} \mathrm{L}^{-1}$. Under the conditions employed to achieve such removal, the calculated OPEX of the MF-AOP process is in the range of $£ 0.32-0.40 \mathrm{~m}^{-3}-50-70 \%$ higher than the MF-RO process but without the requirement for concentrate management.

Removal of the most recalcitrant MP metaldehyde (MA) by more than $75 \%$ demands improved transmittance of the wastewater using either a downstream reverse osmosis (RO) process or supplementary activated carbon (AC). Whilst the MF-RO-AOP process is around $20 \%$ lower in OPEX than the MF-AOP and MF-AC-AOP options and provides a higher water quality, a significant waste stream volume is generated in the form of the concentrate 
stream. The OPEX of the enhanced, three-stage processes can be up to 2.2 times that of the standard MF-RO process.

\section{Acknowledgments}

The authors would like to thank Thames Water for financially supporting the study. Special acknowledgment goes to the whole Innovation Reuse team (Juliette Hatt and Marie Raffin in particular) for their technical support and assistance and the analytical laboratories for their contribution to the production of the data presented.

\section{$5 \quad$ References}

Autin et al., 2013. The impact of background organic matter and alkalinity on the degradation of the pesticide metaldehyde by two advanced oxidation processes: UV/H2O2 and UV/TiO2. Water Research 47 (6), 2041-2049.

Autin, O., Hart, J., Jarvis, P., MacAdam, J., Parsons, S.A., Jefferson, B., 2012. Comparison of UV/H2O2 and UV/TiO2 for the degradation of metaldehyde: Kinetics and the impact of background organics. Water Research 46 (17), 5655-5662.

Baeza, C., Knappe, D. R. U., 2011. Transformation kinetics of biochemically active compounds in low-pressure UV photolysis and UV/H2O2 advanced oxidation processes. Water Res. 45, 4531-4543.

Benotti, M.J., Stanford, B.D., Wert, E.C., Snyder, S.A., 2009. Evaluation of a photocatalytic reactor membrane pilot system for the removal of pharmaceuticals and endocrine disrupting compound from water. Water Research 43 (6), 1513-1522.

Bolton, J. R., Bircher, K. G., Tumas, W. and Tolman. C. A., 2001. Figures-of-Merit for the Technical Development and Application of Advanced Oxidation Technologies for both Electric- and Solar-Driven Systems. Pure \& Applied Chemistry 73 (4), 627-637.

Box G.E.P., Behnken D.W., 1960. Some new three level designs for the study of quantitative variables. Technometrics 2 (4), p. 455-475.

Desbrow, C. Routledge E.J. Brighty, G.C. Sumpter J.P. and Waldock, M., 1998. Identification of estrogenic chemicals in STW effluent. 1. Chemical fractionation and in vitro biological screening. Environmental Science \& Technology 32 (11), 1549-1558.

EC, 2000. European Community Directive 2000/60/EC of the European Parliament and of the Council on establishing a framework for the Community action in the field of water policy. Official Journal of European Community 22/12/00, L327, 1-73.

Energy EU., 2012. http://www.energy.eu/ Website accessed 19th Sept. 2012.

Galbraith, M., Shu, M.-M., Davies, S.H., Masten, S.J., 1992. Use of ozone, ozone, peroxide, and ozone/ UV for the generation of $\mathrm{OH}$ radicals to oxidize chlorinated organics. Presented at the 24th Mid-Atalntic Industrial Waste Conference, Morgantown, WV, 411-430.

Garcia, N., Moreno, J., Cartmell, E., Rodriguez-Roda, I., and Judd, S., 2013. The cost and performance of an MF-RO/NF plant for trace metals removal, Desalination 309 181-186

Hatt., J.W., Germain, E., Judd, S.J., 2013. Granular activated carbon for removal of organic matter and turbidity from secondary wastewater. Water Science \& Technology 67 (4), 846853. 
Hernandez, R., Zappi, M., Colucci, J., Jones, R., 2002. Comparing the performance of various advanced oxidation processes for treatment of acetone contaminated water. Journal of Hazardous Materials 92, 33-50.

Holm, P., 2011. Linking water quality to human health and environment: The fate of micropollutants. Series: Working Paper Series / Institute of Water Policy, National University of Singapore; IWP/WP, No. 3

Hotchkiss, A.K., Rider, C.V., Blystone, C.R., Wilson, V.S., Hartig, P.C., Ankley, G.T., Foster, P.M., Gray, C.L., Earl Gray, L., 2008. Fifteen years after "wingspread" environmental endocrine disrupters and human and wildlife health: where we are today and where we need to go. Toxicological Sciences. 105 (2), 235-259.

IJpelaar, G.F., Harmsen, D., Sharpless, C.M., Linden, K.G., Kruithof, J.C., 2006. Fluence Monitoring in UV Disinfection Systems: Development of a Fluence Meter, AwwaRF report 91110.

IJpelaar, G.F., Harmsen, D.J.H., Beerendonk, E.F., van Leerdam, R.C., Metz, D.H., Knol, A.H., Fulmer, A., Krijnen, S., 2010. Comparison of low pressure and medium pressure UV lamps for $\mathrm{UV} / \mathrm{H} 2 \mathrm{O} 2$ treatment for natural waters containing micro pollutants. Ozone: Science Engineering 32 (5), 329-337.

Katsoyiannis, I.A., Canonica, S., Von Gunten, U., 2011. Efficiency and energy requirements for the transformation of organic micropollutants by ozone, $\mathrm{O}_{3} / \mathrm{H}_{2} \mathrm{O}_{2}$ and $\mathrm{UV} / \mathrm{H}_{2} \mathrm{O}_{2}$. Water Research 45, 3811-3822.

Liao, C.H., Gurol, M.D., 1995. Chemical oxidation by photolytic decomposition of hydrogen peroxide. Environmental Science \& Technology 29 (12), 3007-3014.

Linden, K.G., Rosenfeldt, E.J., Kullman, S.W., 2007. UV/H2O2 degradation of endocrinedisrupting chemicals in water evaluated via toxicity assays. Water Science \& Technology 55 (12) 313-319.

Matilainen, A., Sillanpää, M., 2010. Removal of natural organic matter from drinking water by advanced oxidation processes. Chemosphere 80, 351-365.

MWH Global, 2007. City of San Diego Advanced Water Treatment Research Studies. Final Report, City of San Diego.

Poussade, Y., Roux, A., Walker, T., Zavlanos, V., 2009. Advanced oxdidation for indirect potable reuse - A practical application in Australia. Water Science \& Technology 60 (9), 2419-2424.

Raffin, 2012. Optimisation of membrane technology for water reuse, $\mathrm{PhD}$ thesis, Cranfield University.

Raffin, M., Germain, E., Judd S., 2011. Optimising operation of an integrated membrane system (IMS) - A Box-Behnken approach. Desalination 273 (1) 136-141.

Raffin, M., Shiffar, A., Judd, S.J., 2013. A review of membrane-based water reuse plants: trends and implications. Environmental Technology, in press.

Rosario-Ortiz, F.I., Wert, E.C., Snyder, S.A., 2010. Evaluation of UV/H2O2 treatment for the oxidation of pharmaceuticals in wastewater. Water Research 44, 1440-1448.

Rosenfeldt, E.J., Linden., K.G., 2004. Degradation of endocrine disrupting chemicals bisphenol A, ethinyl estradiol, and estradiol during UV photolysis and advanced oxidation processes. Environmental Science \& Technology 38 (20), 5476-5483. 
Royce, A., Khoo., K., Festger, A., Muller, J., Stefan, M., Mao, T., Cairns, B., 2010. UV disinfection fundamentals. In: The guidebook to membrane technology for wastewater reclamation, edited by Wilf, M. Ch. 18. 1st Ed., Balaban Desalination Publications, Hopkinton, USA.

Sanches, S., Crespo, M.T. B., Pereria, V.J., 2010. Drinking water treatment of priority pesticides using low pressure UV photolysis and advanced oxidation processes. Water Res. 44, 1809-1818.

Stefan, M., 2004. UV Photolysis: background. In: Advanced Oxidation Processes for Water and Wastewater Treatment, edited by S. Parsons. Ch 2. IWA, London.

Snyder, S.A., Wert, E.C., Lei, H.D., Westerhoff, P., Yoon, Y., 2007. Removal of EDCs and Pharmaceuitcals in Drinking and Reuse Treatment Processes. Awwa Research Foundation, Denver CO.T

WSR, 2000. The Water Supply (Water Quality) Regulations (WSR) 2000. The Stationary Office Limited, London, ISBN 0110973844.

Water UK, 2009. Water Company Proposed PR09 Catchment Management Schemes. November 2009, 15-16. 